\title{
Might anything be plain good?
}

\author{
Thomas Byrne ${ }^{1}$
}

(c) The Author(s) 2016. This article is published with open access at Springerlink.com

\begin{abstract}
G.E. Moore said that rightness was obviously a matter of maximising plain goodness. Peter Geach and Judith Thomson disagree. They have both argued that 'good' is not a predicative adjective, but only ever an attributive adjective: just like 'big.' And just as there is no such thing as plain bigness but only ever big for or as a so-and-so, there is also no such thing as plain goodness. They conclude that Moore's goodness is thus a nonsense. However attention has been drawn to a weakness in their arguments. Mahrad Almotahari and Adam Hosein have sought to plug that weakness. If their plug holds, then there is no goodness. Doing most of their work is the following premise: adjective $\varphi$ is predicative only if it can be used predicatively in ' $\mathrm{x}$ is a $\varphi \mathrm{K}$ ' otherwise it is attributive. In this paper I argue that this premise is false, that their plug does not hold and that if one is to reject plain goodness it will have to be for other reasons.
\end{abstract}

Keywords Plain goodness · Thomson · Moore · Predicative · Attributive · Gradable adjective

\section{Introduction}

G.E. Moore said that rightness was obviously a matter of maximising plain goodness (1903: $§ 2, \S 17, \S 89 ; 1912: 232) .{ }^{1}$ But what of this plain goodness? It definitely possesses some intuitive appeal; lawn mowers might be good for cutting

\footnotetext{
1 Throughout, I refer to this goodness in a number of ways: 'plain goodness,' 'goodness simpliciter,' 'being plain good' and so on. The literature in general is similarly varying.

Thomas Byrne

thomas.byrne@kcl.ac.uk

1 Philosophy Building, King's College London, Strand, London WC2R 2LS, UK
} 
grass, spoons good for spooning, songs for dancing to, but other things don't seem to be good in that same way. Knowledge just is good, right? And beauty and love, and perhaps friendship too. They aren't good for something or in certain ways, but just plain good. ${ }^{2}$

Peter Geach and Judith Thomson (henceforth $G \& T$ ) disagree. They have both argued that there is no such property as the property of plain goodness, that nothing is plain good and that Moore's goodness is a nonsense (Geach 1956; Thomson 1997, 2008). However attention has been drawn to a weakness in their arguments. Mahrad Almotahari and Adam Hosein (2015) (henceforth $A \& H$ ) have sought to plug that weakness. ${ }^{3}$ If their plug holds, then there is no goodness. ${ }^{4}$ In this paper, I argue that it does not hold and that neither A\&H nor G\&T have shown that there is no such thing as plain goodness. ${ }^{5}$

\section{The Old Argument and the Improved Argument}

The general argument against Moore is simple. Suppose there is the property of plain goodness. If there is, then surely we can say certain things are plain goodthat knowledge, or love, etc. are plain good. Yet it is argued that 'good' is logically never a predicative adjective, but instead always an attributive adjective. 'Acidic' is a predicative adjective. The claim ' $\mathrm{x}$ is acidic' is coherent, and things are plain acidic: lemon juice is acidic, for example. ${ }^{6}$ In contrast, 'big' is an attributive adjective, ' $\mathrm{x}$ is big' is not coherent by itself, and nothing is just plain big, but instead big relative to some implicit or explicit standard: the mouse is big...for a mouse and so on. Goodness, the argument goes, is not like acidity, but instead like bigness. Just as there is no such property of being plain big or bigness simpliciter, there is no such property as the property of being plain good or goodness simpliciter. Thus ' $\mathrm{x}$ is plain

\footnotetext{
${ }^{2}$ More correctly, they aren't just good for something or in certain ways; of course, they are good in certain ways too.

3 A\&H describe themselves as "present[ing] an argument, inspired by Geach and Thomson, which isn't susceptible to the same objections but which supports the same conclusion" (1485).

4 If there is no goodness then Moore's consequentialism is without a coherent value theory and the whole account unravels from the off. Further implications extend beyond ethics. Consider, for example, Linda Zagzebski's following introduction to the value problem in epistemology: "It is almost always taken for granted that knowledge is good, better than true belief simpliciter, but it is remarkably difficult to explain what it is about knowledge that makes it better. I call this "the value problem" (2003: 12-13 my emphasis)." The problem itself (or, at least, this common formulation of the problem) is incoherent if $\mathrm{A} \& \mathrm{H}$ are right and there is no such property as being plain good.

5 Rowland (2016) discusses various other arguments for goodness simpliciter scepticism. For instance, the argument that people do not use 'good' predicatively outside of the philosophy department. Or the argument that if 'good' is predicative in ' $\mathrm{x}$ is good' then there should be a connection between that meaning of 'good' and the meaning of 'good' in ' $\mathrm{x}$ is a good $\mathrm{K}$.'

6 Geach's example was 'red.' However, as Thomson points out, 'red' can be both contextual and ambiguous ('red wine' for example) and this clouds things (2008: Addendum 1).
} 
good' is either incoherent or, instead, telegraphic (telegraphic for something like $x$ is good as a $k$ or ...for $k)^{7}$

$\mathrm{A} \& \mathrm{H}$ argue in that vein as follows:

Suppose for the sake of argument that the property of being (simply) good exists...

(P1) If there's a property of being good, then we can entertain the property of being good in thought.

(P2) If we can entertain the property of being good in thought, then we can use the word 'good' predicatively in a literal utterance of 'a is good' and thus express the property of being good.

(P3) If we can use the word 'good' predicatively in a literal utterance of 'a is good' and thus express the property of being good, then we can use the word 'good' predicatively in a literal utterance of ' $\mathrm{a}$ is a good $\mathrm{K}$ ' and thus express the property of being good. ${ }^{8}$

(P4) But we can't use the word 'good' predicatively in sentences of the form 'a is a good $\mathrm{K}$ '?

(C1) Therefore, contrary to our initial supposition, there's no property of being good. $(1490)^{10}$

(P1) and (P2) rule out the possibility of goodness existing solely beyond our ken. ${ }^{11}$ (P4) is what G\&T also argue in order to also conclude (C1). Therefore whatever extra work $\mathrm{A} \& \mathrm{H}$ are doing, it is being performed by (P3). In order to assess that premise and its role, we must first understand G\&T's original argument. G\&T arrive at (P4) via the following test for determining whether an adjective is predicative or attributive (or both $)^{12}$ :

\footnotetext{
7 Geach and Thomson diverge here. Geach pushed for there "only being a good or bad so-and-so" (34). Thomson considers ' $\mathrm{x}$ is good for Alfred' and concludes that "here no substantive needs to be understood ... For what K could it plausibly be thought that being good for Alfred is being a good K?" (1997: 135). Thomson seems right on this point.

8 A\&H also provide an abbreviated paraphrase: (P3) "says that if one can use 'good' predicatively in 'a is good', then one can also use 'good' predicatively in 'a is a good $\mathrm{K}$ '."

9 My focus in this paper is (P3), but (P4) also strikes me as questionable. All the examples considered by G\&T and A\&H involve $x$ s such that ' $\mathrm{x}$ is good' is false. If an $\mathrm{x}$ is used such that ' $\mathrm{x}$ is good' is true (or, at least, plausible), then a predicative reading of 'good' in ' $\mathrm{x}$ is a good $\mathrm{K}$ ' is clearer. Consider: 'love is a good source of creativity' said in response to the claim that all sources of creativity are immoral, for instance. In such a context, the predicative reading of 'good' is clear. And contrast that with A\&H's 'pain is a good source of creativity.' A predicative reading there would entail that 'pain is good' and that alone seems sufficiently contradictory to block such a reading.

10 A\&H add two further steps to reject Moorean consequentialism: “(P5) If there's no property of being good, then it's not the case that what we ought to do is produce more instances of goodness. (C2) Therefore, standard [Moorean] consequentialism is false." (1490).

11 If goodness is to play a role in our ethical lives it presumably is something we can access conceptually and linguistically. Consequentialism, for instance, could not be prescriptive if goodness were inaccessible to us in these ways. It would be very odd if Moore (or a Moorean) were to deny these premises. See A\&H (2015: 1498).

12 Henceforth, I'm using "is predicative" as shorthand for "can be predicative."
} 
Adjective $\varphi$ is predicative only if, for things $\mathrm{K}_{1}$ and $\mathrm{K}_{2}$, ' $\mathrm{x}$ is a $\varphi \mathrm{K}_{1}$ ' and ' $\mathrm{x}$ is a $K_{2}$ ' entails ' $x$ is a $\varphi K_{2}$,' otherwise it is attributive (Geach 1956: 33; Thomson 2008: 4-5). ${ }^{13}$

For example: ' $\mathrm{x}$ is an acidic drink' and ' $\mathrm{x}$ is a liquid' entail ' $\mathrm{x}$ is an acidic liquid,' and thus 'acidic' is a predicative adjective. Contrasted with ' $x$ is a big flea' and ' $x$ is an animal' which do not entail that ' $x$ is a big animal,' and thus 'big' is attributive. Moving forward, I call this $G \& T$ 's Test.

G\&T conclude that 'good' fails their test. For 'John is a good assassin' and 'John is a priest' do not entail 'John is a good priest' — good priests do not moonlight as assassins. Similarly: 'pain is a good source of creativity' and 'pain is a sensation' do not entail 'pain is a good sensation.' And lastly: 'Joan is a good lawyer' and 'Joan is a singer' do not entail 'Joan is a good singer.' ${ }^{14}$ Thus, by the lights of G\&T's Test, the grammar of 'good' is such that it cannot be used predicatively, but instead only ever attributively. And thus good is an attributive property. And thus there is no such thing as being just plain good-that is (C1).

However, there is an immediate problem with G\&T's argument. Yes, the Moorean should concede that if 'good' is always used attributively then good is an attributive property and thus ' $x$ is good' is incoherent. They can also concede that 'good' is indeed always used attributively in ' $\mathrm{x}$ is a good K.' Yet the Moorean can push back and rightly deny that that second concession is sufficient to satisfy the antecedent of the first; just because 'good' is always attributive in ' $\mathrm{x}$ is a good $\mathrm{K}$,' why should that be taken to have any necessary bearing upon its logical form in ' $\mathrm{x}$ is good.' There is nothing contradictory in granting that 'good' is (always) attributive in certain locutions, while maintaining that it is nonetheless predicative in others. Nothing that has been said prevents the Moorean from holding resolute and insisting that good is used predicatively in 'pleasure/knowledge/love is good,' despite it being attributive elsewhere. Simply put, the argument is not valid in its current form. More needs to be said if G\&T's final conclusion is to hold. ${ }^{15,16}$

Enter $\mathrm{A} \& \mathrm{H}$ and $(\mathrm{P} 3)$. The purpose of (P3) is to block the above objection to G\&T's argument by denying the possibility of an adjective $\varphi$ always being attributive in the form ' $\mathrm{x}$ is a $\varphi \mathrm{K}$,' yet predicative in ' $\mathrm{x}$ is $\varphi$.' With that possibility

\footnotetext{
13 Geach's explicitly formulated test is: Adjective $\varphi$ is predicative only if, for any object $K$, ' $x$ is a $\varphi \mathrm{K}$ ' entails both ' $\mathrm{x}$ is $\varphi$ ' and ' $\mathrm{x}$ is a $\mathrm{K}$ ', otherwise $\varphi$ is attributive. However his commentary on this test presumably inspired Thomson's formulation of the test described here. He says: “...for if these analyses were legitimate, a simple argument would show that a big flea is a big animal and a small elephant a small animal" (1956: 33).

14 Note, 'Joan is a plain good lawyer' returns the same result. A\&H consider this way out for the consequentialist; they rightly reject it.

15 Much has been said on this point. See, for example, Arneson (2010: 732-733), Kraut (2011: Ch 30), Sinnott-Armstrong (2003: §2), Sturgeon (2010: 751).

16 Thomson does push back a bit. She wonders exactly what one might mean were they to use 'good' predicatively in ' $\mathrm{x}$ is good' (2008: 14; 2010: 754). Lots has been said on that front and this is not the time to examine the nature of goodness (for such an examination see, for example, Zimmerman (2001)). However, I think it is worth mentioning that Moore would not see a case to answer. After all, he took goodness to be a simple concept with no further analysis possible: “...my answer is that good is good, and that is the end of the matter" and "...you cannot explain what good is" (1903: §§6-7).
} 
rejected, when the Moorean retreats from G\&Ts argument to "but it is predicative in 'pleasure is good,'” A\&H can respond, "but it can't be, for if it were, then we would also be able to use 'good' predicatively in ' $x$ is a good K,' but we can't." The structure of their argument is therefore different to that of G\&T's. Their test (henceforth TEST), introduced by (P3), is the following:

Adjective $\varphi$ is predicative only if it can be used predicatively in ' $x$ is a $\varphi \mathrm{K}$ ' otherwise it is attributive.

And in order to determine the outcome of TEST, they employ G\&T's Test.

Thus A\&H's overall strategy is as follows. TEST says that if $\varphi$ is predicative, then we can use $\varphi$ predicatively in ' $\mathrm{x}$ is a $\varphi \mathrm{K}$.' To determine whether or not we can use $\varphi$ predicatively in ' $\mathrm{x}$ is a $\varphi \mathrm{K}$ ' we have G\&T's Test. As G\&T's Test returns 'good' as always attributive in ' $\mathrm{x}$ is a good K,' TEST then returns 'good' as not predicative and thus ultimately there is no property of being plain good.

Now, the addition of (P3) renders A\&H's argument valid. And in doing so, it renders it both immune to the earlier objection and stronger than what preceded it. Everything rides upon it. Yet, why should we accept (P3)? A\&H say the following:

Well, suppose that the use of 'good' in 'Pleasure is good' expresses goodness. Then 'Pleasure is good' is true iff pleasure falls in the extension of 'good'. But then surely the use of 'good' in 'Pleasure is good' can be combined with a common noun, 'sensation', to yield a complex verb phrase, 'is a good sensation', whose extension is determined by intersecting the extensions of 'good' and 'sensation'. (1492)

The "surely" in the third sentence indicates an appeal to common sense and common sense does perhaps rule in their favour-at least on first glance. However, there are limits to how far that should take an idea. Consider, for example, a different linguistic rule that carries at least as much common sense support as (P3): if ' $x$ is a $\varphi K$ ' then ' $x$ is a $K$ '; if ' $x$ is a hairy dog' then ' $x$ is a dog.' Yet, now consider ' $\mathrm{x}$ is a fake gun.' Not only does this not entail ' $\mathrm{x}$ is a gun' it actually entails ' $\mathrm{x}$ is not a gun' (Morzycki 2014: 24)! ${ }^{17}$ First glances are not definitive.

What about second glances? Recap where things stand for A\&H. We have adjectives $\varphi$ that are predicative in ' $\mathrm{x}$ is $\varphi$,' that are always predicative in ' $\mathrm{x}$ is a $\varphi$ $\mathrm{K}$ '-'acidic,' 'red' and so on. A\&H also grant there there exist adjectives that are predicative in ' $\mathrm{x}$ is $\varphi$,' yet fluctuate between predicative and attributive in ' $\mathrm{x}$ is a $\varphi$ K.' 'Famous' is one such adjective (A\&H 1488-1489). ${ }^{18}$ And now (P3) says that it is not possible for any adjective $\varphi$ that is predicative in ' $x$ is $\varphi$ ' to be always attributive in ' $\mathrm{x}$ is a $\varphi \mathrm{K}$.' I represent this below:

\footnotetext{
17 Morzyki calls such adjectives privative (\$2.2.5).

18 Thomson also discusses 'famous' (2008: 13-14).
} 
Possible readings of adjective $\varphi$ in ' $x$ is a $\varphi \mathrm{K}$ '

(for $\varphi$ that is predicative in ' $x$ is $\varphi$ ')

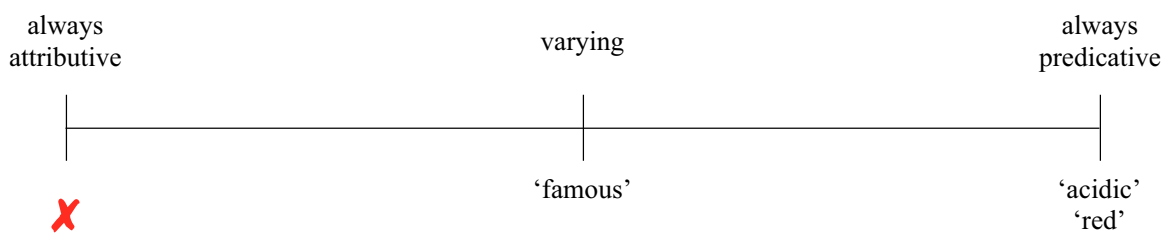

Now, it could be the case that (P3) is true, but it certainly isn't obvious to me that it must be; it certainly isn't obvious that no adjective could possibly replace the cross. If there exist such predicative adjectives $\varphi$ that are always predicative in ' $\mathrm{x}$ is a $\varphi \mathrm{K}$,' and $\varphi s$ that are sometimes predicative and sometimes attributive in that same locution, then it is not beyond the realm of common sense to suggest that there might also be $\varphi s$ that are always attributive in ' $\mathrm{x}$ is a $\varphi \mathrm{K}$ ' despite also being predicative in ' $x$ is $\varphi$.' At the very least, it isn't sufficiently far beyond that realm for common sense alone to carry the premise. Again, none of this says anything of the truth or falsity of (P3). But simply that A\&H must say more if anyone hostile to their project is to accept (P3) and, ultimately, be swayed by their argument.

That said, in what follows I seek to demonstrate that saying more would be moot. Specifically, I seek to demonstrate that TEST is not valid and, as a result, that we should not accept (P3). If I am right, then A\&H's argument is no better than G\&T's and, ultimately, A\&H provide no good reason to deny the predicative reading of 'good' in ' $\mathrm{x}$ is good.'

\section{Why Accept (P3)?}

If TEST is valid for determining the grammar of adjective $\varphi$, then it must be reliable in doing so. Its reliability rules out the possibility of false positives by ensuring that if $\varphi$ can be predicative in ' $x$ is a $\varphi \mathrm{K}$ ' and thus pass TEST, then $\varphi$ is indeed predicative. It also rules out false negatives; if there is no predicative reading of $\varphi$ in ' $x$ is a $\varphi \mathrm{K}$ ' and $\varphi$ thus fails TEST, it must indeed be the case that $\varphi$ is not predicative. If TEST admits of either false positives or false negatives then the implications are clear: TEST is not a reliable indicator as to the grammar of $\varphi$. There can be no reason to think TEST has false positives. However, the same does not hold for false negatives. I take ' $f$ lat' to be an adjective that TEST incorrectly returns as not predicative. To show this I have to demonstrate both that (a) 'flat' cannot be predicative in ' $\mathrm{x}$ is a flat $\mathrm{K}$ ' and that (b) 'flat' can be predicative in ' $\mathrm{x}$ is flat.'

The short version goes like this. Statements of the form ' $\mathrm{x}$ is a flat $\mathrm{K}$ ' can only be read as ' $\mathrm{x}$ is flat ...for a $\mathrm{K}$ ': ' $\mathrm{x}$ is a flat field' reads as ' $\mathrm{x}$ is flat...for a field,' ' $\mathrm{x}$ is a flat snooker table' as ' $\mathrm{x}$ is flat...for a snooker table' and so on. 'Flat' in ' $\mathrm{x}$ is a flat $\mathrm{K}$ ' functions just like 'big' in analogous locutions. And thus ' $\mathrm{x}$ is a flat $\mathrm{K}_{1}$ ' and ' $\mathrm{x}$ is a $\mathrm{K}_{2}$ ' do not entail ' $\mathrm{x}$ is a flat $\mathrm{K}_{2}$ '. So 'flat' fails G\&T's Test and by TEST's lights, 
'flat' is not predicative. Nonetheless, I can say of something that it is plain flat and that is when I want to say it has no bumps whatsoever. You can imagine someone who knows no better thinking the surface of a still lake has no bumps whatsoever and saying as such: "the surface of the lake is flat." And that it is not actually plain flat has no bearing upon whether someone can predicate such flatness of it. ${ }^{19}$ Alternatively, a geometer might remark that certain "geometric abstractions are flat." And so on. Of course, the devil is in the detail. I take (a) and (b) in turn.

\subsection{Considering ' $\mathrm{x}$ is a flat $\mathrm{K}$ '}

'Flat' in ' $\mathrm{x}$ is a flat $\mathrm{K}$ ' functions in the same way as any run-of-the-mill gradable adjective. 'Tall,' 'rich,' and 'heavy' are gradable adjectives and they are each associated with a certain gradient property-height, wealth and weight, respectively. They lend themselves to comparatives ('John is taller than Bob'/'The A31 is flatter than the M25'), to degree modifiers ('Jane is very rich'/'The snooker table is very flat') and, sometimes but not always, to measurability ('Billie is $180 \mathrm{lb}$. heavy' but not ' $\mathrm{x}$ is 7 units flat'). ${ }^{20}$ Importantly, the interpretation of a gradable adjective $\alpha$ in ' $\mathrm{x}$ is an $\alpha \mathrm{K}$ ' is context dependent and the truth conditions of the statement fluctuate accordingly. ' $\mathrm{K}$ ' provides the context and that context determines a comparison class of contextually similar objects and the truth conditions of the statement are defined in reference to that class. ${ }^{21}$ Consider, for example, 'Michael Jordan is a tall man': the comparison class would be other men. While for 'Michael Jordan is a tall living thing,' the comparison class would also include women and giraffes and redwoods. From this point, various analyses compete as to exactly how the truth conditions are determined, but the subtleties do not bear on the issue at hand. $^{22} \mathrm{~A}$ well established analysis appeals to degrees and scales-I follow that lead. $^{23}$

It holds that the property associated with a gradable adjective provides a scale consisting of a set of degrees or points, dense and totally ordered according to that property. Gradable adjectives map their argument to a degree on the relevant

\footnotetext{
19 Recall, the argument under discussion is a conceptual one, not a metaphysical one. One can hold that nothing is flat nor good, yet maintain that the respective concepts are nonetheless perfectly coherent. Rowland (2016) distinguishes between conceptual- and metaphysical goodness scepticism. Only the former is in play here.

${ }^{20}$ Klein (1980: 6) takes an adjective to be gradable if and only if "(i) it can occur in predicative position, i.e. after copular verbs such as be, seem, become. [And] (ii) it can be preceded by degree modifiers such as very and fairly".

21 This isn't quite right and the context can be determined by more than just K. Travis considers a red maple leaf that is painted green and the claim 'this is a green leaf.' 'Leaf' alone isn't sufficient to determine the semantics of the statement as it would mean one thing said by horticulturalist and another said by someone making a decorative collage (1994: 171-172). Relatedly, consider someone searching for a book to prop up a television and, on finding an appropriately thick book, saying 'this is a good book.' In doing so, they aren't saying that it is good as a book but instead as a prop (Szabó 2001: 134). That said, this increased subtlety doesn't bear on my purposes here.

22 See Morzycki (2014: \$3.6).

23 See, for example Flieger (2009), Kennedy (2007), Kennedy and McNally (2005), Klein (1980), Morzycki (2014).
} 
scale-or, more aptly, to a range of degrees on the relevant scale. For example, ' $\mathrm{x}$ is tall' maps $\mathrm{x}$ to a range above a certain degree of the height scale. The context and comparison class determine the relevant degree. Again, consider 'Michael Jordan is a tall man.' The comparison class of men determines a degree $\delta$ on the height scale, say $6 \mathrm{ft}$, such that ' $\mathrm{x}$ is a tall man' is true if $\mathrm{x}$ 's height is greater than or equal to $\delta$ (and $\mathrm{x}$ is a man). ${ }^{24}$

Notably, all of G\&T's example attributive adjectives were gradable, and it's clear why such adjectives fail G\&T's Test. Consider Geach's flea:

(i) ' $x$ is a big flea'

(ii) ' $\mathrm{x}$ is an animal'

(iii) ' $\mathrm{x}$ is a big animal'

The truth of (i) tells us that x's weight is greater than some degree $\delta_{1}$ on the weight scale, where $\delta_{1}$ is determined by the comparison class of other fleas-say $1 \mathrm{mg}$. Yet, this has no logical bearing upon whether x's weight is also greater than degree $\delta_{2}$ as determined by the comparison class of animals. And thus (iii) does not follow from (i) an (ii).

Of course, there are many contingent relationships that can be drawn between degrees as determined by different comparison classes, and thus similar arguments can be provided that possess a whiff of rightness, but it is not a logical rightness. Consider:

(iv) 'Jumbo is a big elephant'

(v) 'Jumbo is an animal'

(vi) $\therefore$ 'Jumbo is a big animal'

Yet, this too is invalid. While it can be validated with the addition of a premise - something akin to 'elephants are big animals,' and thus $\delta_{1}$ for elephants is greater than $\delta_{2}$ for animals - this says nothing of the original's validity. Another thought might be that when $\mathrm{K}_{2}$ 's comparison class is a subset of $\mathrm{K}_{1}$ 's, then the argument would be valid:

(vii) 'Bob is a big person'

(viii) 'Bob is a child'

(ix) $\therefore$ 'Bob is a big child'

But, again, the appearance of rightness is riding off the contingent fact that children tend to be smaller than adults (and $\delta_{1}>\delta_{2}$ ) and not off anything logical. To see this, consider:

\footnotetext{
${ }^{24}$ The indeterminacy of that exact point leads to the vagueness of 'expensive.' Although gradable adjectives tend to also be vague adjectives, the two are conceptually distinct. The former is characterised by varying degrees, while the latter is characterised by borderline cases. Flieger (2009: §5.2.2).
} 
(x) 'Bob is a big person'

(xi) 'Bob is a giant'

(xii) $\therefore$ 'Bob is a big giant'

Just as children are a subset of people, so too are giants, yet in this case $\delta_{2}>\delta_{1}$. Ultimately, the relationship between degrees $\delta_{1}$ and $\delta_{2}$ as determined by distinct comparison classes is a contingent relationship, not a logical one. And thus, gradable adjectives $\alpha$ are attributive in ' $\mathrm{x}$ is an $\alpha \mathrm{K}$.' This explains why G\&T's original examples worked as they did.

'Flat' in ' $\mathrm{x}$ is a flat $\mathrm{K}$ ' functions in the same way as these gradable adjectives. Its associated property is bumpiness and the scale is ordered accordingly. When one says ' $\mathrm{x}$ is a flat $\mathrm{K}$ ' they are saying that $\mathrm{x}$ 's bumpiness is less than some degree of bumpiness as determined by the comparison class of Ks. Consider:

(xiii) ' $\mathrm{x}$ is a flat road'

(xiv) ' $\mathrm{x}$ is a man made object'

(xv) $\therefore$ ' $\mathrm{x}$ is a flat man made object' ${ }^{25}$

What (xiii) tells us, if true, is that x's bumpiness is less than degree $\delta_{1}$ on the bumpiness scale, where $\delta_{1}$ is determined by the comparison class of roads. Yet, as with 'big' above, that fact has no logical bearing upon whether x's bumpiness is less than $\delta_{2}$ as determined by the comparison class of man made objects. And rightly so: while a road with no bumps bigger than $1 \mathrm{~mm}$ would be very flat for a road, it would make for a mediocre tennis court and an awful snooker table.

Again, arguments that seem correct are possible:

(xvi) ' $\mathrm{x}$ is a flat man made object'

(xvii) ' $\mathrm{x}$ is a road'

(xiii) $\therefore$ ' $\mathrm{x}$ is a flat road'

But, this is invalid just like (iv)-(vi) and (vii)-(ix). All-in-all, 'flat' is just like 'big' and friends; 'flat' fails G\&T's Test, thus (a).

\subsection{Considering ' $x$ is flat'}

If 'flat' is predicative in ' $\mathrm{x}$ is flat,' then 'flat' must diverge from the gradable adjectives or, at least, be a special breed of them. After all, ' $x$ is tall,' ' $x$ is big' and ' $x$ is heavy' are all either telegraphic (' $x$ is $\alpha$...for a K'), where what's omitted determines the comparison class and, ultimately, the truth conditions of the statement, or they are incoherent. Without a comparison class, these statements

\footnotetext{
${ }^{25}$ A\&H utilise a cancellation clause added to the end of a statement: '... —of course, $\mathrm{x}$ isn't $\varphi$ as/for a K.' The purpose of the cancellation clause is to better bring out a valid predicative reading, if such a reading exists (1493). However, it is no help here: ' $x$ is a flat man made object — of course, it's not flat for a man made object' simply smacks of contradiction.
} 
make no sense: 'tall for a what?,' 'a big what?' and so on. Indeed, TEST gets things right where 'tall,' 'big' and 'heavy' are concerned. So what of 'flat'? By looking closely at the scales of the adjectives concerned-particularly at the limits of those scales-we can see why 'flat' diverges from the others.

Kennedy and McNally (2005) differentiate gradable adjectives according to their scale structure. ${ }^{26}$ Particularly they focus on whether a scale has maximal and/or minimal degrees: if a scale has both it is (fully) closed; if just a maximal, it is upperclosed; if just a minimal, lower-closed; if neither, open (\$3). The length scale is open; for every degree of length, there is another longer and another shorter, which is to say the scale has neither maximum nor minimum degrees. ${ }^{27}$ The same goes for the scales of weight and height and of size generally. Cost, meanwhile, is lowerclosed; something can have no cost— "it cost me nothing"/"it was free"-yet it can also always be more expensive and thus the scale has no maximum. Straightness (of a line/stick/etc.) is upper-closed: somethings (could) have no bends in them whatsoever, but there is no limit to how bendy something might be. Lastly, the scale that measures fill is (fully) closed. Something can have absolutely nothing in it or, conversely, have no room for anything else (Kennedy and McNally 2005: §3).

A defining characteristic of scales that have maximal or minimal degrees is that the relevant adjectives lend themselves to modification with modifiers akin to 'plain' or 'absolutely' or ' $100 \%$.' Conversely, such modification is infelicitous with an open scale (or with the open end of a partially closed scale). Consider: ' $x$ is $100 \%$ full' or ' $\mathrm{x}$ is absolutely straight' vs ' $\mathrm{x}$ is plain short' or ' $\mathrm{x}$ is perfectly bendy.' It is clear why this characteristic is defining: in ' $x$ is absolutely/plain/etc. $\alpha$ ' the adjective $\alpha$ maps the argument to that maximal or minimal degree and, if that is to be felicitous, the degree in question must exist. For example, ' $\mathrm{x}$ is perfectly straight' maps $x$ to the maximal degree of straightness - a degree that admits of no bends whatsoever. The same does not hold for ' $x$ is perfectly tall,' since there is no maximal degree in that scale that 'tall' can map the argument on to.

The structures of the relevant scales explain why 'flat' in ' $x$ is flat' diverges from other gradable adjectives. The bumpiness scale is lower-closed as something can have no bumps whatsoever and ' $\mathrm{x}$ is plain flat,' '...100\% flat' etc. are perfectly felicitous. Thus, ' $\mathrm{x}$ is plain flat' maps $\mathrm{x}$ to the minimum degree of the bumpiness scale, without recourse to context nor comparison class. Such a statement is appropriate just when someone wants to say of $\mathrm{x}$ that it has no bumps whatsoever: when someone wants to attribute such a dearth of bumps to a still lake or to a geometric abstraction. However, the same cannot be said of 'tall,' 'big' and 'heavy'-all of which are associated with open scales.

Ultimately, the property of plain flatness exists, it is the minimum degree on the bumpiness scale and one can predicate such a property of things accordingly. 'Flat' is predicative in ' $\mathrm{x}$ is flat.' This is (b).

\footnotetext{
${ }^{26}$ So too do Rotstein and Winter (2004), but I focus on Kennedy and McNally (2005). Morzycki (2014: §3.7.2) also provides commentary.

${ }^{27}$ One might be tempted to push for a minimal element, a length of 0 . However this doesn't bear out linguistically; something of zero length is also said to have "no length." See Kennedy and McNally (2005: 10) for more discussion.
} 


\section{Conclusion}

Gradable adjectives $\alpha$ are attributive in ' $\mathrm{x}$ is an $\alpha \mathrm{K}$.' However, I've shown that certain gradable adjectives, those that are associated with the closed end of a scale, can be predicative in ' $\mathrm{x}$ is $\alpha$.' Following Unger (1975), I call these absolute adjectives. 'Flat' is one such adjective, and it is in good company: 'empty,' 'full,' 'straight,' and 'pure' are others. That such adjectives exist is sufficient to show that TEST is not reliable and, in turn, not valid as a determinant of the grammar of adjectives $\varphi$ - 'good' included. (P3) must be rejected and, ultimately, A\&H's argument does not plug the hole in G\&T's.

What can A\&H say in response? They can highlight that 'good,' unlike 'flat,' is not an absolute adjective and, in doing so, obtain a little room to manoeuvre. They could, for instance, adjust (P3) so as to take into account these recalcitrant adjectives and simply stipulate their way out of the objection:

(P3)' If we can use the word 'good' predicatively in a literal utterance of 'a is good' and thus express the property of being good, then either we can use the word 'good' predicatively in a literal utterance of ' $\mathrm{a}$ is a good $\mathrm{K}$ ' and thus express the property of being good or 'good' is an absolute adjective.

And then adjust TEST accordingly:

TEST $^{\prime}$ Adjective $\varphi$ is predicative only if either it can be used predicatively in

' $\mathrm{x}$ is a $\varphi \mathrm{K}$ ' or it is an absolute adjective, otherwise it is attributive.

As 'good' isn't an absolute adjective, nothing said here stops TEST' returning 'good' as attributive-just as A\&H require.

But then why accept (P3)'? I suggested earlier that (P3) itself had little motivating it beyond an already overstretched appeal to common sense, yet (P3) ${ }^{\prime}$ is sufficiently ad hoc to cast off whatever intuitive appeal its predecessor might carry. So, again, why accept $(\mathrm{P} 3)^{\prime}$ ? I see no reason, other than to let the tail wag the dog.

Lastly, why presume that 'flat' and the absolute adjectives are the only adjectives that TEST erroneously returns as not predicative? I have focused on 'flat' because its semantics are well established and because, when examined, those semantics paint a clear picture as to why TEST returns the wrong result in that case. But that focus was not exhaustive and it is likely other similar adjectives exist. SinnottArmstrong, for instance, suggests 'apologetic' and, on quick examination, it seems he might be right. 'Pippa is plain unapologetic' certainly seems coherent, and it is true if Pippa has a history of failing to apologise. But, conversely, 'Pippa is an unapologetic Catholic' and 'Pippa is a farmer' do not entail that 'Pippa is an unapologetic farmer' (2003: 84).

All in all, (P3) is false and A\&H's argument is no stronger than G\&T's. Just as G\&T's argument said nothing as to why the grammar of 'good' in one locution must bear upon its grammar in another, nor does A\&H's. Ultimately, they provide no reason to doubt that 'knowledge/love/beauty is good' is coherent. If plain goodness is to be rejected, it will have to be for other reasons. 
Acknowledgments I would like to thank Joseph Byrne, Nat Hansen, Eliot Michaelson and Saawani Raje for discussing these arguments with me. I am particularly grateful to David Galloway, Clayton Littlejohn, Michael O'Sullivan and Jake Wojtowicz for reading complete drafts and commenting extensively. Lastly, my thanks goes to an anonymous reviewer for Philosophical Studies for their helpful comments.

Open Access This article is distributed under the terms of the Creative Commons Attribution 4.0 International License (http://creativecommons.org/licenses/by/4.0/), which permits unrestricted use, distribution, and reproduction in any medium, provided you give appropriate credit to the original author(s) and the source, provide a link to the Creative Commons license, and indicate if changes were made.

\section{References}

Almotahari, M., \& Hosein, A. (2015). Is anything plain good? Philosophical Studies, 172, 1485-1508. Arneson, R. (2010). Good period. Analysis, 70, 731-744.

Flieger. J. C. (2009). Gradable adjectives and the semantics of locatives (Doctoral dissertation). Retrieved from Edinburgh Research Archive.

Geach, P. (1956). Good and evil. Analysis, 17, 33-42.

Kennedy, C. (2007). Vagueness and grammar: The semantics of relative and absolute gradable adjectives. Linguistics and Philosophy, 30, 1-45.

Kennedy, C., \& McNally, L. (2005). Scale structure, degree modification, and the semantics of gradable predicates. Language, 81(2), 345-381.

Klein, E. (1980). A semantics for positive and comparative adjectives. Linguistics and Philosophy, 4, $1-45$.

Kraut, R. (2011). Against absolute goodness. Oxford: Oxford University Press.

Moore, G. E. (1903). Principia ethica. Cambridge: Cambridge University Press.

Moore, G. E. (1912). Ethics. London: Williams and Norgate.

Morzycki, M. (2014). Modification draft. Cambridge: Cambridge University Press.

Rotstein, C., \& Winter, Y. (2004). Total adjectives vs. partial adjectives: Scale structure and higher-order modifiers. Natural Language Semantics, 12(3), 259-288.

Rowland, R. (2016). In defence of good simpliciter. Philosophical Studies, 173(5), 1371-1391.

Sinnot-Armstrong, W. (2003). For goodness' sake. The Southern Journal of Philosophy, 91, 83-91.

Sturgeon, N. (2010). Normativity. Analysis, 70, 744-753.

Szabó, Z. G. (2001). Adjectives in context. Perspectives on Semantics, pragmatics, and discourse, 119-146.

Thomson, J. J. (1997). The right and the good. Journal of Philosophy, 94, 273-298.

Thomson, J. J. (2008). Normativity. Chicago: Open Court.

Thomson, J. J. (2010). Reply to Critics. Analysis, 70(4), 753-764.

Travis, C. (1994). On Constraints of Generality. Proceedings of the Aristotelian Society New Series, 44, 165-188.

Unger, P. (1975). Ignorance: A case for scepticism. Oxford: Oxford University Press.

Zagzebski, L. (2003). The search for the source of the epistemic good. Metaphilosophy, 34, 12-28.

Zimmerman, M. (2001). The nature of intrinsic value. Lanham: Rowman and Littlefield. 